medRxiv preprint doi: https://doi.org/10.1101/2021.04.27.21256115; this version posted April 29, 2021. The copyright holder for this preprint

(which was not certified by peer review) is the author/funder, who has granted medRxiv a license to display the preprint in perpetuity.

All rights reserved. No reuse allowed without permission.

\title{
2 Applications of Digital Microscopy and Densely Connected Convolutional Neural Networks for 3 Automated Quantitation of Babesia-Infected Erythrocytes
}

\section{Thomas JS Durant ${ }^{1 *}$; Sarah Dudgeon ${ }^{2,3}$; Jacob McPadden ${ }^{4}$; Anisia Simpson ${ }^{5}$; Nathan Price ${ }^{6}$; Wade}

5 Schulz ${ }^{1,2,6}$; Richard Torres ${ }^{1}$; Eben M Olson ${ }^{1}$

6

1 - Department of Laboratory Medicine, at Yale School of Medicine, New Haven, CT.

2 - Center for Outcomes Research and Evaluation, at Yale New Haven Hospital, New Haven, CT.

3-Biological and Biomedical Sciences, at Yale University, New Haven, CT.

4 - Department of Neonatology, at Yale School of Medicine, New Haven, CT.

5 - Department of Laboratory Medicine, at Yale New Haven Hospital, New Haven, CT.

6 - Center for Computational Health, at Yale New Haven Hospital, New Haven, CT.

* To whom correspondence should be addressed:

Thomas JS Durant

Department of Laboratory Medicine, 55 Park Street PS345D, New Haven, CT 06511.

Tel.: 203-688-2301; E-mail: thomas.durant@yale.edu

\section{Abbreviations:}

AUC: Area Under the Curve

FN: False Negative

FP: False Positive

IG: Integrated Gradient

MLS: Medical Laboratory Scientist

MLS-RS: Medical Laboratory Scientist-Reference Standard

RBC: Red blood cell

TN: True Negative

TP: True Positive

XAI: Explainable Artificial Intelligence

Running title: Machine Learning for Babesia Quantitation

Disclaimers: None

Support: Academy of Clinical Laboratory Physicians and Scientists: Paul E. Strandjord Young Investigator Research Grant Keywords: machine learning, convolutional neural networks, peripheral blood smear, erythrocyte, red blood cells, babesia, image analysis. 
medRxiv preprint doi: https://doi.org/10.1101/2021.04.27.21256115; this version posted April 29, 2021. The copyright holder for this preprint (which was not certified by peer review) is the author/funder, who has granted medRxiv a license to display the preprint in perpetuity.

All rights reserved. No reuse allowed without permission.

Background: Clinical babesiosis is diagnosed, and parasite burden is determined, by microscopic inspection of a thick or thin Giemsa-stained peripheral blood smear. However, quantitative analysis by manual microscopy is subject to observer bias, slide distribution errors, statistical sampling error, recording errors, and is inherently burdensome from time management and workflow efficiency standpoints. As such, methods for the automated measurement of percent parasitemia in digital microscopic images of peripheral blood smears could improve clinical accuracy, relative to the predicate method.

Methods: Individual erythrocyte images (shape: 70x70×3) were manually labeled as "parasite" or "normal" and were used to train a model for binary image classification. The best model was then used to calculate percent parasitemia from a clinical validation dataset, and values were compared to a clinical reference value. Lastly, model interpretability was examined using an integrated gradient to 50 identify pixels most likely to influence classification decisions.

51 Results: The precision and recall of the model during development testing were 0.92 and 1.00,

52 respectively. In clinical validation, the model returned increasing positive signal with increasing mean

53 reference value. However, there were two highly erroneous false positive values returned by the model.

54 Lastly, the model incorrectly assessed three cases well above the clinical threshold of $10 \%$. The

55 integrated gradient suggested potential sources of false positives including rouleaux formations, cell

56 boundaries, and precipitate as deterministic factors in negative erythrocyte images.

57 Conclusions: While the model demonstrated highly accurate single cell classification and correctly

58 assessed most slides, several false positives were highly incorrect. This project highlights the need for 59 integrated testing of ML-based models, even when models in the development phase perform well. 
medRxiv preprint doi: https://doi.org/10.1101/2021.04.27.21256115; this version posted April 29, 2021. The copyright holder for this preprint (which was not certified by peer review) is the author/funder, who has granted medRxiv a license to display the preprint in perpetuity.

All rights reserved. No reuse allowed without permission.

\section{INTRODUCTION:}

62 Clinical Babesiosis is a haemoprotozoan disease that is most commonly transmitted from animals to

63 humans by invertebrate vectors (e.g., Ixodes scapularis, the black legged deer tick)(1). In the United

64 States, $95 \%$ of cases occur in the Northeast and Upper Midwest states, occurring primarily between May

65 and October. In the state of Connecticut, the seroprevalence has been shown to range between 0.3-

$6617.8 \%$, with the number of reported cases being approximately 44 per 100,000 (2). Disease severity can

67 range from asymptomatic to severe, the latter of which may lead to life-threatening scenarios. Severe

68 disease is more common in specific at-risk populations including those who are post-splenectomy,

69 immunocompromised, or older than 50 years of age. The all-cause mortality of babesiosis has been

70 estimated as $<1 \%$ for clinical cases, and approximately $10 \%$ for iatrogenic cases (e.g., transfusion-

71 transmitted) (2).

The diagnostic gold standard for babesiosis is microscopic inspection of thick, or thin, Giemsa-

73 stained peripheral blood smear (1). If Babesia spp is identified, the degree of parasitemia is used to guide patient management strategies. For mild disease, or minimal parasitemia, antimicrobials are the preferred therapy. However, the American Society for Apheresis (ASFA) guidelines state that severe babesiosis is a category II indication for red blood cell (RBC) exchange. Severe disease is determined

77 both by clinical and laboratory criteria including significant parasitemia (e.g., $>10 \%$ ), the presence of

78 comorbidities (e.g., asplenia), or severe symptoms such as, disseminated intravascular coagulation or

79 multiorgan failure (2). While there is no consensus on when to discontinue RBC exchange, it is

81 quantified daily alongside continued RBC exchange until parasite burden decreases below 5\% $(2,3)$. 
medRxiv preprint doi: https://doi.org/10.1101/2021.04.27.21256115; this version posted April 29, 2021. The copyright holder for this preprint (which was not certified by peer review) is the author/funder, who has granted medRxiv a license to display the preprint in perpetuity.

All rights reserved. No reuse allowed without permission.

immersion objective. While this process requires minimal laboratory equipment, it does require an experienced MLS to ensure optimal accuracy and reproducibility for serial measurement purposes (1). In addition, quantitative analysis by manual microscopy is subject to observer bias, slide distribution errors, statistical sampling error and recording errors, and is inherently burdensome from time management and workflow efficiency standpoints $(4,5)$. Such limitations can mislead or delay therapeutic decision making, particularly in the context of therapeutic RBC exchange. Accordingly, there remains a significant need to develop automated methods to optimize the cost, efficiency, and accuracy of quantitative analysis.

The progress made in computer vision and machine learning $(\mathrm{ML})$ technology over the last decade has encouraged a corresponding increase in their implementation in the clinical laboratory (6).

With the decreasing availability of experienced medical laboratory scientists, evaluating ML-based software capabilities without expert operator review remains an important consideration in study design $(7,8)$. To this end, we sought to develop and evaluate the accuracy of a an ML-based method for the automated measurement of percent parasitemia in digital microscopic images of peripheral blood smears. Specifically, we sought to describe the accuracy of parasitemia measurements, as determined by ML-based software, relative to an MLS-derived reference standard (MLS-RS). We hypothesized that results generated by the ML-based software would show superior precision to MLS-RS while achieving clinically comparable numerical results to the average MLS-RS.

\section{METHODS:}

Hardware and Operating Systems:

Computation for model training was performed on a local Linux server (NVIDIA DGX Server Version 4.6.0) (GNU/Linux 4.15.0-122-generic x86_64) running Ubuntu (version: 18.04.5 LTS). Processing 
medRxiv preprint doi: https://doi.org/10.1101/2021.04.27.21256115; this version posted April 29, 2021. The copyright holder for this preprint (which was not certified by peer review) is the author/funder, who has granted medRxiv a license to display the preprint in perpetuity.

All rights reserved. No reuse allowed without permission.

108

109

110

hardware included 80 CPUs (Intel(R) Xeon(R) CPU E5-2698 v4 @ 2.20GHz) and 8 GPUs (Tesla V100SXM2-16GB) using CUDA Toolkit (version: 11.0).

\section{Data Set Curation:}

This study has been reviewed and approved by the Yale University Internal Review Board (IRB\# 2000020244). Clinical blood samples were originally collected as part of routine clinical workflow in lavender-top (EDTA) tubes for screen and quantitation of Babesia spp. Slides and concomitant digital images of the associated peripheral blood smears, which were found by to be positive for Babesia spp and negative for Malaria spp (BinaxNOW Malaria; Abbott, Chicago, IL), were flagged for inclusion using previously described methods (9-11). Slides and the concomitant digital images of Babesia-negative samples were collected from the routine clinical workflow throughout the study period and reviewed by a clinical pathologist for the absence of Babesia spp prior to inclusion.

Slides and images were separated into two distinct groups, representing separate patient cohorts: (1) The model development dataset and (2) the clinical validation dataset. The model development dataset was used for training, validation, and preliminary evaluation of the cell classification model. The clinical validation dataset was used as a second, 'external' validation dataset to evaluate how the model would perform in a clinical implementation workflow, as compared to a predicate method-based reference standard.

All peripheral blood smears were created and imaged on a DI-60 Integrated Slide Processing System (Cellavision AB, Lund, Sweden). The DI-60 uses a 100X-objective and a 0.5X magnifier prior to imaging, rendering an effective magnification of 50X. Images are 3-channel RGB, with a resolution of 5 pixels per micron. In the model development dataset, slide images had an average height and width of 2884 pixels (95\% Cl: 2882-2885) and 2867 pixels (95\% Cl: 2865-2868) (Figure $1 \mathrm{~A})$. Slides included in the model development dataset were imaged a single time. Slides included in the clinical validation dataset 
medRxiv preprint doi: https://doi.org/10.1101/2021.04.27.21256115; this version posted April 29, 2021. The copyright holder for this preprint (which was not certified by peer review) is the author/funder, who has granted medRxiv a license to display the preprint in perpetuity.

All rights reserved. No reuse allowed without permission.

132 were imaged three times on the same scanner to compute intra-precision for quantitation of Babesia

133 spp during subsequent portions of the study.

134

Cell Labeling for Model Development Dataset:

Slide-level images from the model development dataset were uploaded to a custom-built web

137 application for labeling of individual erythrocytes using one of two labels: (1) parasite or (2) normal.

138 Using the web application, annotators marked central X-Y coordinates of infected and non-infected

erythrocytes (Figure 1B). X-Y coordinates of cell centers were then used to crop individual erythrocytes

from the slide-level parent image into $70 \times 70$ pixel, 3-channel image arrays. These $70 \times 70 \times 3$ images were

141 then paired with their corresponding label of either 'parasite' or 'normal' (Figure 1C). The labeling

142 process was performed by a single laboratory medicine attending and author of this manuscript (TJD).

143 As a post-processing step, $X-Y$ coordinates which were within 140 pixels of another set of $X-Y$

144 coordinates were removed from the dataset following completion of the annotation process. This was

145 done to ensure that there was no overlap of images in the final development dataset which, if present,

146 could have resulted in part of an image being represented in both the training and validation and test

147 datasets, leading to overfitting, or an over-optimistic estimate of model performance.

Ultimately, the final dataset used for model development consisted of non-overlapping,

149 individual erythrocyte images (shape: 70x70x3) with an associated label of 'parasite' or 'normal'. These

150 data were split and used to train, validate, and test the image classification model. The model

151 development dataset was divided 80:20 into train and test datasets, respectively (Figure 1D). The train

152 dataset was further subdivided 70:30 into train and validation datasets, respectively. The train and

153 validation datasets were used during the training of the image classification model (Figure 1E). The test

154 dataset was used to evaluate model performance following completion of training (Figure 1F). 
medRxiv preprint doi: https://doi.org/10.1101/2021.04.27.21256115; this version posted April 29, 2021. The copyright holder for this preprint (which was not certified by peer review) is the author/funder, who has granted medRxiv a license to display the preprint in perpetuity.

All rights reserved. No reuse allowed without permission.

Network Implementation:

157 For image classification, the authors implemented DenseNet121 as the base model, initialized with 158 pretrained weights from ImageNet (7). Densely connected neural networks were first described by

159 Huang et al. and are a commonly used architecture for learning image classification tasks (8). This neural 160 network was chosen based on previously published performance metrics comparable with current state 161 of the art models, and because it uses relatively fewer parameters, making it faster to train and easily 162 portable (12). Base model layers were not frozen and were configured as trainable. DenseNet121 was 163 combined with a custom set of prediction layers, specific to this image classification task. These included 164 a 2-dimensional global average pooling layer, a dropout layer, and a densely connected layer with 165 sigmoid activation function for binary classification. The Adam method was used for gradient-based 166 optimization. In total, there were $7,038,529$ parameters, $6,954,881$ of which were trainable. The 167 network was implemented using Tensorflow (version: 2.4.0rc0), Tensorflow-gpu (version: 2.4.0rc0) and 168 Python (version: 3.6.9).

171 Train dataset images were subjected to label preserving augmentation prior to being served as input to 172 the network. Image augmentation included random horizontal and vertical flips, random rotation, 173 random translation, random zoom, random contrast adjustments, and random brightness adjustments.

174 Lastly, due to the imbalanced nature of our training dataset the 'parasite' class was oversampled to 175 produce a 1:1 ratio of parasite and normal images during training. The network was trained for a total of 17650 epochs (i.e., iterations) over the complete training dataset. The validation dataset was used to 
medRxiv preprint doi: https://doi.org/10.1101/2021.04.27.21256115; this version posted April 29, 2021. The copyright holder for this preprint (which was not certified by peer review) is the author/funder, who has granted medRxiv a license to display the preprint in perpetuity.

All rights reserved. No reuse allowed without permission.

177

178

179

180

181

182

183

184

185

186

187

188

189

190

191

192 slide in the clinical validation dataset was independently evaluated by three MLS's with 26,6 , and 4

monitor model performance during training for subsequent tuning according to the calculated binary cross-entropy loss. Model parameters were saved following a reduction in the binary cross-entropy loss, calculated from the validation dataset after each epoch. The initial learning rate was set to $1 \mathrm{e}-5$ and decreased by a factor of 10 if validation loss did not improve after 5 epochs. The total training process was repeated three times using unique random seed initializers to evaluate variability in train performance metrics. Performance metrics monitored during training included true positives (TP), false positives (FP), true negatives (TN), false negatives (FN), binary accuracy, precision (i.e., positive predictive value) (TP / (TP + FP)), recall (i.e., sensitivity) (TP / (TP + FN), and area under the receiver operator characteristic curve (AUC). These were calculated on both train and validation datasets following the completion of each epoch. Following model training, the best model parameters (i.e., those which achieved the lowest validation loss) were used to evaluate individually labeled erythrocytes in the test dataset. Cells with a probability score greater than or equal to 0.5 were assigned 'parasite' prediction labels. Test predictions were then used to calculate the performance metrics for the test dataset. Similarly, the 'best model' was used to evaluate cells in the clinical validation protocol.

\section{Clinical Validation Protocol:}

Following model development, a separate set of peripheral blood smear slides were used to assess the accuracy of the model in a simulated clinical workflow. Due to the inherent variability seen with quantitative analysis by microscopy, a clinical reference standard consisting of multiple measurements was compiled for comparisons between the model and the predicate method. Accordingly, each glass years of experience for MLS A, B, and C, respectively. The clinical validation slides were shuffled, specimen numbers on the glass slides were covered, and a box containing the clinical validations slides 
medRxiv preprint doi: https://doi.org/10.1101/2021.04.27.21256115; this version posted April 29, 2021. The copyright holder for this preprint (which was not certified by peer review) is the author/funder, who has granted medRxiv a license to display the preprint in perpetuity.

All rights reserved. No reuse allowed without permission.

200

201

202

203

204

205

206

207

was given to each of the MLS' for independent evaluation. Each MLS evaluated all clinical validation slides three separate times (Figure 2A). In total, this process generated 9 results of percent parasitemia for each slide in the clinical validation dataset. These data were used to calculate the average percent parasitemia across all 9 reads which was used as the MLS-RS for each case/sample (Figure 2B). Of note, the lower limit of quantitation for percent parasitemia in the clinical laboratory at our institution is $1 \%$ and results below this value are reported out as $<1 \%$ in routine practice. For the purposes of this study, MLSs were asked to record the precise parasitemia value, including those below $1 \%$, to allow for a completely empirical comparison against the model.

For the model-based method, as mentioned, each slide in the clinical validation dataset was scanned three separate times by the DI-60 (Figure 2C). A custom cell-segmentation script was then used to crop individual erythrocytes from the peripheral blood smear image (Figure 2D). Cell-segmentation was implemented using OpenCV (version: 4.2.0.34) using contour-based (cv.findContours()). Individual erythrocytes (shape: $70 \times 70 \times 3$ ) were then provided as input to the best model, as defined in the development protocol, to yield a predicted class (i.e., 'parasite' or 'normal') for each individually cropped erythrocyte (Figure 2E). Following classification of individual erythrocytes, the number of cells with the predicted label of 'parasite' were divided by number of total cells classified to yield the quantification of percent parasitemia. This process was done one time for each image with three images per specimen, yielding a total of 3 parasitemia results per slide (Figure 2F).

parasitemia were made using a variety of approaches: (1) bar plot visualization; (2) regression and Bland-Altman plots; (3) quantitative agreement of model percent parasitemia in relation to \pm 2 SD of the average MLS-RS percent parasitemia $(n=9)$ for each case in the clinical validation dataset; (4) categorical agreement of percent parasitemia bins; (5) categorical agreement around the clinical decision threshold 
medRxiv preprint doi: https://doi.org/10.1101/2021.04.27.21256115; this version posted April 29, 2021. The copyright holder for this preprint (which was not certified by peer review) is the author/funder, who has granted medRxiv a license to display the preprint in perpetuity.

All rights reserved. No reuse allowed without permission.

223 implementation. This was done on the test images in the model development dataset.

of $10 \%$. Precision was assessed using the coefficient of variation, which was calculated on a case-wise basis across the MLS $(n=9)$ and model results $(n=3)$.

\section{Model Interpretability:}

In an effort to examine the relationship between model predictions and image features, we implemented an explainable artificial intelligence (XAI) technique based on axiomatic attribution for deep networks and known as Integrated Gradients (IG) (13). While the methods of IG are outside the scope of this report, the general purpose is to identify pixels within each image which most heavily influence a model's prediction, and derived from the gradient (i.e., slope or derivative) of the prediction function relative to each feature (i.e., pixel). For the purposes of this report we attempted to provide representative samples of what we observed when reviewing the images derived from an IG

236 RESULTS:

Dataset Curation:

238 A total of 96 unique slides were included in this study. Of these, 71 slides were included in the 239 development dataset, 28 of which were found to be positive for Babesia spp by routine clinical 240 workflow. A total of 14,633 individual erythrocyte images were initially labeled. Of those, 2,019 images 241 that had overlapping cells were removed, yielding a final development dataset of 11,388 erythrocytes

242 labeled as normal and 1,226 with a parasite. The mean number of labeled cells per unique slide was 178 243 (SD 63; range 1-286). Of the slide-level images which were Babesia-positive, the mean parasitemia was $2446.5 \%$ (SD 4.5; range 1.0-20.0). The clinical validation dataset consisted of the remaining 25 slides, of 245 which 64\% ( $n=16)$ were Babesia-positive. The mean parasitemia among the Babesia-positive slides in the 246 clinical validation dataset was 8.9\% (SD 9.4; range 1.0-29.2). 
medRxiv preprint doi: https://doi.org/10.1101/2021.04.27.21256115; this version posted April 29, 2021. The copyright holder for this preprint (which was not certified by peer review) is the author/funder, who has granted medRxiv a license to display the preprint in perpetuity.

\section{Model Development:}

249 The cell classification model was trained 3 separate times. Each training replicate consisted of 50 epochs

250 (iterations). Learning rates decayed following validation loss plateau across all training replicates, with

251 the final value ranging from 1e-8 to 1e-9. Minimum validation loss was observed following completion

252 of training epoch 22,22 , and 31 for each of the training replicates, with an average binary cross-entropy

253 of 0.024 (SD 0.003). Binary cross-entropy loss was plotted and inspected for positive divergence of

254 validation loss, relative to training loss, as an empirical indicator of overfitting. This was observed

255 minimally in the later training epochs (Figure 3A). Precision, recall, and AUC for asymptotically

256 approached model performance limits which were concordant with plateaus of validation loss,

257 indicating model improvement to be unlikely to occur with additional training iterations (Figures 3B-D).

258 Training replicate 3 achieved the lowest validation loss during training (0.021) and was subsequently

259 used for evaluation of the test and clinical validation datasets. Model predictions on the test dataset

260 resulted in 20 false positives and zero false negatives. The precision and recall were 0.92 and 1.00,

261 respectively (Figure 4A). The binary classification accuracy was 0.99 . The distribution of predicted

262 probabilities for erythrocytes in the test dataset was visualized and demonstrated a predominantly

263 bimodal distribution between the predicted classes (Figure 4B).

Clinical Validation of Model-Based Method

266 A total of 25 unique slides were identified for evaluation in the clinical validation set, 16 of which were

267 found to be positive for Babesia spp by routine clinical workflow. Of those 16, one (Case \#15) was

268 excluded from analysis, as per the consensus recommendation of the participating MLS' due to

269 excessive artifact, Howell-Jolly bodies, and only rare, dying parasites. The remaining slides were 
medRxiv preprint doi: https://doi.org/10.1101/2021.04.27.21256115; this version posted April 29, 2021. The copyright holder for this preprint (which was not certified by peer review) is the author/funder, who has granted medRxiv a license to display the preprint in perpetuity.

All rights reserved. No reuse allowed without permission. negative case in the clinical validation set, were also examined and demonstrated erroneous activation

evaluated in three separate instances by each of the MLS' with an average parasitemia ranging from $<0.1 \%$ to $38.5 \%$ (Supplemental Table 1 and Supplemental Figure 1).

Model classification demonstrated an increasing positive signal (i.e., higher parasite count) with respect to the MLS-RS; however, the automated model also demonstrated spurious positive signal with the negative cases (Cases 16-25). In addition, the model returned highly erroneous false positive signal on cases 11 and 16, relative to the MLS-RS (Figure 5). A simple linear regression was performed to evaluate the concordance between the MLS-RS and the model predictions. The regression equation was determined as: $4.78+0.55 x$ with correlation coefficient $\left(R^{2}\right)$ of 0.244 (Figure $\left.6 A\right)$. With cases 11 and 16 removed, the regression equation is calculated as: $1.68+0.68 \mathrm{x}$ with an $\mathrm{R}^{2}$ of 0.916 . Bland-Altman plots were also assessed for bias trends, and similarly demonstrate erroneous positive signal on the low end and erroneously low positive signal on the high end (Figure 6A and 6B).

Of the 14 positive cases included in the clinical validation dataset, 10 were within 2 SD of the MLS-RS mean. However, only 7 were concordant between the model and MLS-RS with regards to the percent parasitemia bins. In addition, there were three major errors by the model-based method, which were defined as discordance around the clinical decision point of $10 \%$ parasitemia. Of the 14 positive cases, the MLS-RS CV was less than $20 \%$ in only 3 cases, whereas the Model CV was less than $20 \%$ for 10 of the cases (Supplemental Table 2).

\section{Model Interpretability:}

Cells from the test dataset and the clinical validation dataset were evaluated using the IG approach to visualize feature pixel-level activation patterns. Cells from the test dataset generally demonstrated activation of pixels which were near the intra-erythrocytic parasite (Figure 7). Cells from case 25, a on non-parasitic features. Some of these features included erythrocyte abnormalities (e.g., target cell 
medRxiv preprint doi: https://doi.org/10.1101/2021.04.27.21256115; this version posted April 29, 2021. The copyright holder for this preprint (which was not certified by peer review) is the author/funder, who has granted medRxiv a license to display the preprint in perpetuity.

All rights reserved. No reuse allowed without permission.

contours), precipitate, and overlying platelets. In some cases, the model appeared to be focusing on

background pixels which may be indicative of overfitting in some aspects of the model (Figure 8).

\section{DISCUSSION}

298 In this report, we describe an approach to quantifying percent-parasitemia in peripheral blood smears

299 using computer vision and machine learning technology. We sought to examine the accuracy of an ML-

300 based solution without the use of expert operator-reclassification. Since the beginning of modern

301 computing, there has been considerable interest in the optimization of peripheral blood smear review,

302 with published efforts for smear image analysis dating back to the 1970 's $(14,15)$. While previous

303 attempts yielded variable results, recent improvements in computing hardware have led to significant

304 advancements in performance, particularly in the context of object classification tasks (16). Indeed,

305 there has been a resurgence over recent years investigating the application of machine learning-based

306 technologies for classification, speciation, and quantitative tasks using digital images of the peripheral

307 blood smear $(17,18)$. Automated image analysis tools are becoming increasingly available for peripheral

308 smear analysis, however, the scope of FDA approval is limited and classification algorithms demonstrate

309 suboptimal performance without human reclassification $(19,20)$.

We found that in the context of the train-test development cycle, model performance metrics

311 demonstrated highly accurate results. Train and validation loss curves demonstrated minimally

312 appreciable divergence towards the end of training iterations which would imply that there is negligible

313 overfitting with the cell classification model (Figure 3A). The sigmoid activation function used for the

314 classification layer of the model demonstrated good separation between the parasite class and the non-

315 parasite class, with only 20 false positive cells in the test dataset (Figure 4). However, when the model

316 was implemented with contour-based cell segmentation and applied to the clinical validation dataset,

317 method comparison studies with the MLS-RS demonstrated suboptimal concordance with the model- 
medRxiv preprint doi: https://doi.org/10.1101/2021.04.27.21256115; this version posted April 29, 2021. The copyright holder for this preprint (which was not certified by peer review) is the author/funder, who has granted medRxiv a license to display the preprint in perpetuity.

All rights reserved. No reuse allowed without permission.

based method. Simple linear regression between the two methods had a calculated correlation

coefficient (R2) of 0.244 and 0.916 with and without outliers, respectively. In addition, only 7 of the 14

positive cases were concordant between the model and MLS-RS when grouped by percent parasitemia

321 bins. Lastly, there were three major errors by the model-based method, which were defined as

322 discordance around the clinical decision point of 10\% parasitemia (Supplemental Table 2).

324 interrogate the performance of ML-based technology beyond the train-test development cycle. In the

325 clinical validation method-to-method comparison, the model returned highly erroneous positive signal

326 with cases 11 and 16, relative to the MLS-RS (Figure 5). These errors were likely driven, in part, by the

327 quality of the blood smear which contained significant amount of precipitate and rouleaux formations.

328 For blood smear images where there was minimal to no rouleaux formation, visual inspection of

329 contour-based cell segmentation suggested adequate performance (Supplemental Figure 2). However,

330 in the context of significant rouleaux formation, cell segmentation resulted in fewer individual cells

331 identified for evaluation (Supplemental Figure 3 and 4). In combination with overlying precipitate, which

332 can be mistaken for intra-erythrocyte parasites, this can result in a high numerator (i.e., false positives)

333 and a low denominator (i.e., fewer individually segmented cells), which led to artificially elevated

334 parasitemia quantification. Future work in this area could explore the use of ML-based approaches to

335 cell segmentation. However, these approaches would theoretically encounter similar barriers when

336 initializing models with coordinates for segmentation training and would need specific considerations

337 for handling rouleaux formations. During the initial stages of this work, we had found there to be little

338 qualitative difference between computer vision and ML-based segmentation for smears when there was

339 minimal rouleaux formation to contend with (data not shown).

Model interpretability experiments were used to develop an intuitive sense as to what

341 effectuates the observed model behavior, a limitation being that this method only provides an 
medRxiv preprint doi: https://doi.org/10.1101/2021.04.27.21256115; this version posted April 29, 2021. The copyright holder for this preprint (which was not certified by peer review) is the author/funder, who has granted medRxiv a license to display the preprint in perpetuity.

All rights reserved. No reuse allowed without permission.

342 indication of feature importance on individual images and does not offer a mechanism to provide insight

343 across the entire dataset. It also only explains individual feature contributions, but does not examine

344 how feature interactions may contribute to predictions (21). Nonetheless, these experiments revealed

345 that model predictions of the target class, 'parasite', were generally most impacted by pixels spatially

346 related to intraerythrocytic ring-forms (Figure 7). However, there were instances wherein pixel-wise

347 activation patterns were found to be localized outside of the erythrocyte and corresponding to

348 background noise (Supplemental Figure 5). This would suggest that there is some degree of overfitting

349 which is not obviously appreciable through visual inspection of the train and validation loss curves.

350 Integrated gradients also provided some context as to model fallibility when applied to the clinical

351 validation dataset. Cells which were classified as 'parasite' from case 25 demonstrated pixel-wise

352 activation patterns which suggest that the model prediction of the target class was susceptible to

353 influence by features which share similarities to ring-form parasites. Examples of these microscopic

354 features which were associated with localized pixel activation included variations in erythrocyte

355 morphology (e.g., target cell contours) and overlying precipitate or platelets (Figure 8).

In general, model misclassification errors may be remedied by increasing the number of class

357 examples during training. In doing so, the model input space would be more representative of the

358 heterogeneity the model may be expected to encounter with real-world data, relative to a model

359 trained with fewer class examples. However, in the context of training classification models in

360 healthcare, particularly those which rely on cases of low prevalence diseases, increasing the number of

361 training examples can be prohibitive. There are techniques which can be implemented to artificially

362 expand the size of the training dataset (e.g., label-preserving image transformations) and improve

363 model performance and generalizability. However, these techniques are limited in terms of their

364 performance benefits and cannot portray inherent intra-class variability which is not already 
medRxiv preprint doi: https://doi.org/10.1101/2021.04.27.21256115; this version posted April 29, 2021. The copyright holder for this preprint (which was not certified by peer review) is the author/funder, who has granted medRxiv a license to display the preprint in perpetuity.

All rights reserved. No reuse allowed without permission.

represented in the existing training dataset. Overall, results of this study reinforce the need for consistent, artifact-free, high quality data for optimal algorithm performance. whereas approaches leveraging deep learning methods have only recently been described (22). To our

369 knowledge, this is the first published work to focus on the quantitation of Babesia with interpretable

370 clinical results, using images that are derived from routine clinical workflows. Further, we also evaluated

371 the utility of the model-based method using external validation datasets, not commonly done in malaria

372 quantitation studies $(18,23)$. Similar to other published reports, we classified and quantified intracellular

373 parasites using 'per-cell' images (24). Other articles have also described a region-based approach,

374 wherein images containing multiples cells are evaluated for intracellular parasites, and a final

375 quantitative score is ultimately produced (18). However, while there are arguably benefits to each, there

376 is currently no clear advantage to either approach. Indeed, with the increasing breadth of machine

377 learning technologies, there are multiple avenues to pursue for parasite quantitation. Further research

378 is needed to delineate which methods are most performant, scalable, and most easily implemented into

379 clinical workflows, as well as addressing data quality for machine learning implementation in

380 microscopic image-based computer analysis. 
medRxiv preprint doi: https://doi.org/10.1101/2021.04.27.21256115; this version posted April 29, 2021. The copyright holder for this preprint (which was not certified by peer review) is the author/funder, who has granted medRxiv a license to display the preprint in perpetuity. All rights reserved. No reuse allowed without permission.

\section{ACKNOWLEDGEMENTS:}

383 We would like to acknowledge Lisa Mehlin, Holly Base, and Laura Pires for volunteering their time to

384 quantitate Babesia parasites for the purposes of the clinical validation portion of this study. We would

385 also like to acknowledge John Errico and Cai Mayberry for their administrative support of this work. 
medRxiv preprint doi: https://doi.org/10.1101/2021.04.27.21256115; this version posted April 29, 2021. The copyright holder for this preprint (which was not certified by peer review) is the author/funder, who has granted medRxiv a license to display the preprint in perpetuity.

\section{Bibliography}

1. Miller JM, Binnicker MJ, Campbell S, Carroll KC, Chapin KC, Gilligan PH, et al. A guide to utilization of the microbiology laboratory for diagnosis of infectious diseases: 2018 update by the infectious diseases society of america and the american society for microbiology. Clin Infect Dis. 2018;67:e1e94.

2. Padmanabhan A, Connelly-Smith L, Aqui N, Balogun RA, Klingel R, Meyer E, et al. Guidelines on the Use of Therapeutic Apheresis in Clinical Practice - Evidence-Based Approach from the Writing Committee of the American Society for Apheresis: The Eighth Special Issue. J Clin Apher. 2019;34:171-354.

3. Wormser GP, Dattwyler RJ, Shapiro ED, Halperin JJ, Steere AC, Klempner MS, et al. The clinical assessment, treatment, and prevention of lyme disease, human granulocytic anaplasmosis, and babesiosis: clinical practice guidelines by the Infectious Diseases Society of America. Clin Infect Dis. 2006;43:1089-1134.

4. Pierre RV. Peripheral blood film review. The demise of the eyecount leukocyte differential. Clin Lab Med. 2002;22:279-297.

5. Rümke CL. Imprecision of ratio-derived differential leukocyte counts. Blood Cells. 1985;11:, 315.

6. Florin L, Maelegheer K, Muyldermans A, Van Esbroeck M, Nulens E, Emmerechts J. Evaluation of the CellaVision DM96 advanced RBC application for screening and follow-up of malaria infection. Diagn Microbiol Infect Dis. 2018;90:253-256.

7. Garcia E, Kundu I, Kelly M, Soles R. The american society for clinical pathology's 2018 vacancy survey of medical laboratories in the united states. Am J Clin Pathol. 2019;152:155-168.

8. Garcia E, Kundu I, Ali A, Soles R. The American Society for Clinical Pathology's 2016-2017 Vacancy Survey of Medical Laboratories in the United States. Am J Clin Pathol. 2018;149:387-400.

9. McPadden J, Warner F, Young HP, Hurley NC, Pulk RA, Singh A, et al. Clinical Characteristics and Outcomes for 7,995 Patients with SARS-CoV-2 Infection. medRxiv. 2020;

10. Durant TJS, Gong G, Price N, Schulz WL. Bridging the Collaboration Gap: Real-time Identification of Clinical Specimens for Biomedical Research. J Pathol Inform. 2020;11:14.

11. McPadden J, Durant TJ, Bunch DR, Coppi A, Price N, Rodgerson K, et al. Health care and precision medicine research: analysis of a scalable data science platform. J Med Internet Res. 2019;21:e13043.

12. Keras Applications [Internet]. [cited $2021 \mathrm{Feb} 15]$. Available from: https://keras.io/api/applications/

13. Sundararajan M, Taly A, Yan Q. Axiomatic Attribution for Deep Networks. arXiv. 2017;

14. Bacus JW, Belanger MG, Aggarwal RK, Trobaugh FE. Image processing for automated erythrocyte classification. Journal of Histochemistry \& Cytochemistry. 1976;24:195-201.

15. Prewitt JM, Mendelsohn ML. The analysis of cell images. Ann N Y Acad Sci. 1966;128:1035-1053. 
medRxiv preprint doi: https://doi.org/10.1101/2021.04.27.21256115; this version posted April 29, 2021. The copyright holder for this preprint

(which was not certified by peer review) is the author/funder, who has granted medRxiv a license to display the preprint in perpetuity.

All rights reserved. No reuse allowed without permission.

16. Krizhevsky A, Sutskever I, Hinton GE. ImageNet classification with deep convolutional neural networks. Commun ACM. 2012;60:84-90.

17. Durant TJS, Olson EM, Schulz WL, Torres R. Very deep convolutional neural networks for morphologic classification of erythrocytes. Clin Chem. 2017;63:1847-1855.

18. Poostchi M, Silamut K, Maude RJ, Jaeger S, Thoma G. Image analysis and machine learning for detecting malaria. Transl Res. 2018;194:36-55.

19. Yamamoto T, Tabe $\mathrm{Y}$, Ishii K, Itoh S, Maeno I, Matsumoto K, et al. [Performance evaluation of the CellaVision DM96 system in WBC differentials]. Rinsho Byori. 2010;58:884-890.

20. Kratz A, Bengtsson H-I, Casey JE, Keefe JM, Beatrice GH, Grzybek DY, et al. Performance evaluation of the CellaVision DM96 system: WBC differentials by automated digital image analysis supported by an artificial neural network. Am J Clin Pathol. 2005;124:770-781.

21. Integrated gradients | TensorFlow Core [Internet]. [cited 2020 Nov 12]. Available from: https://www.tensorflow.org/tutorials/interpretability/integrated_gradients

22. Liang Z, Powell A, Ersoy I, Poostchi M, Silamut K, Palaniappan K, et al. CNN-based image analysis for malaria diagnosis. 2016 IEEE International Conference on Bioinformatics and Biomedicine (BIBM). IEEE; 2016. page 493-496.

23. Park SH, Han K. Methodologic guide for evaluating clinical performance and effect of artificial intelligence technology for medical diagnosis and prediction. Radiology. 2018;286:800-809.

24. Li S, Yang Q, Jiang H, Cortés-Vecino JA, Zhang Y. Parasitologist-level classification of apicomplexan parasites and host cell with deep cycle transfer learning (DCTL). Bioinformatics. 2020;36:44984505. 
medRxiv preprint doi: https://doi.org/10.1101/2021.04.27.21256115; this version posted April 29, 2021. The copyright holder for this preprint (which was not certified by peer review) is the author/funder, who has granted medRxiv a license to display the preprint in perpetuity.

All rights reserved. No reuse allowed without permission.

FIGURES:

Figure 1: Flow diagram of model development process. (A) Slides included in the model development dataset were imaged a single time by the Cellavision DI-60 and uploaded to a custom-built-web application for label annotation. (B) Central X-Y coordinates of infected (red) and non-infected (blue) erythrocytes were marked on the slide-level images. (C) Central X-Y coordinates were used to crop individual erythrocytes into $70 \times 70$ pixel, 3-channel arrays and paired with the corresponding label of either 'parasite' (red) or 'normal' (blue). (D) Labeled erythrocyte images were collectively divided 80:20 into train and test datasets, respectively. The train dataset was further subdivided 70:30 into train and validation datasets, respectively. (E) The train and validation datasets were used train the image classification model. (F) Following completion of training, the [best model] was used to evaluate model 459 performance using the test dataset.

Figure 2: Flow diagram of clinical validation process. (A) Each peripheral blood smear was evaluated

461 three times, in a blinded fashion, by each MLS. (B) This process yielded a total of 9 parasitemia results

462 for each slide in the clinical validation dataset. These data were used to calculate the average

463 parasitemia across all 9 reads which was used as the clinical reference standard for each case. (C) Each

464 glass slide in the clinical validation dataset was imaged three separate times by the Cellavision DI-60. (D)

465 Contour-based cell segmentation was used to extract individual erythrocytes from the DI-60 slide-level images as 70x70x3 cropped images. (E) Individually cropped erythrocytes were independently evaluated

467 by the [best model] to yield a predicted class (i.e., 'parasite' or 'normal'). (F) The number of cells with

468 the predicted label of 'parasite' were divided by number of total cells classified to yield the parasitemia 469 result. This process was done one time for each DI-60 image. With three images per specimen, this 470 yielded a total of 3 parasitemia results per slide, which were used to calculate an average parasitemia 471 result for each specimen. 
medRxiv preprint doi: https://doi.org/10.1101/2021.04.27.21256115; this version posted April 29, 2021. The copyright holder for this preprint (which was not certified by peer review) is the author/funder, who has granted medRxiv a license to display the preprint in perpetuity.

All rights reserved. No reuse allowed without permission.

472 Figure 3: Model performance metrics plotted as a function of training epochs (iterations). (A) Train and

473 validation loss. (B) Train and validation recall (sensitivity). (C) Train and validation area under the

474 receiver operator characteristic curve. (D) Train and validation precision (positive predictive value).

$475 \quad$ Figure 4: Model classification results on test dataset. (A) Confusion matrix of actual versus predicted 476 labels. (B) Per-cell probability distribution of model predicted class with actual labels depicted in color

477 (red $=$ parasite) $($ blue $=$ normal). X-axis: The probability of the predicted class being 'parasite'. Y-axis:

478 Random number between 0 and 1 was assigned to each cell for better visualizing data points. Green

479 dotted line: Decision threshold for prediction label of 'parasite' - i.e., cells with a predicted probability

480 of $\geq 0.5$ are labeled as 'parasite'.

481 Figure 5: Bar plot of mean percent parasitemia for the MLS-RS $(n=9)$ and the model-based method $(n=3)$.

482 Error bars represent 1 standard deviation.

483 Figure 6: Visualizations for method-to-method comparison of MLS-RS and model-based method. (A) XY-

484 scatter plot with regression line overlay (red-dotted line represents 95\% confidence interval of

485 regression). (B) Bland-Altman absolute bias plot. (C) Bland-Altman percent bias plot.

486 Figure 7: Integrated gradient (IG) visualizations including the original image, the pixel-wise IG

487 attribution mask, and the overlay of the two. Images are from the model development test dataset. (A

488 and B) Representative examples from the 'parasite' class. ( $C$ and $D$ ) Representative examples from the

489 'normal' class.

490 Figure 8: Integrated gradient (IG) visualizations including the original image and an overlay of the pixel-

491 wise IG attribution mask and the original image. Images are from Case \#25 of the clinical validation

492 dataset and are those which were predicted as belonging to the 'parasite' class. 


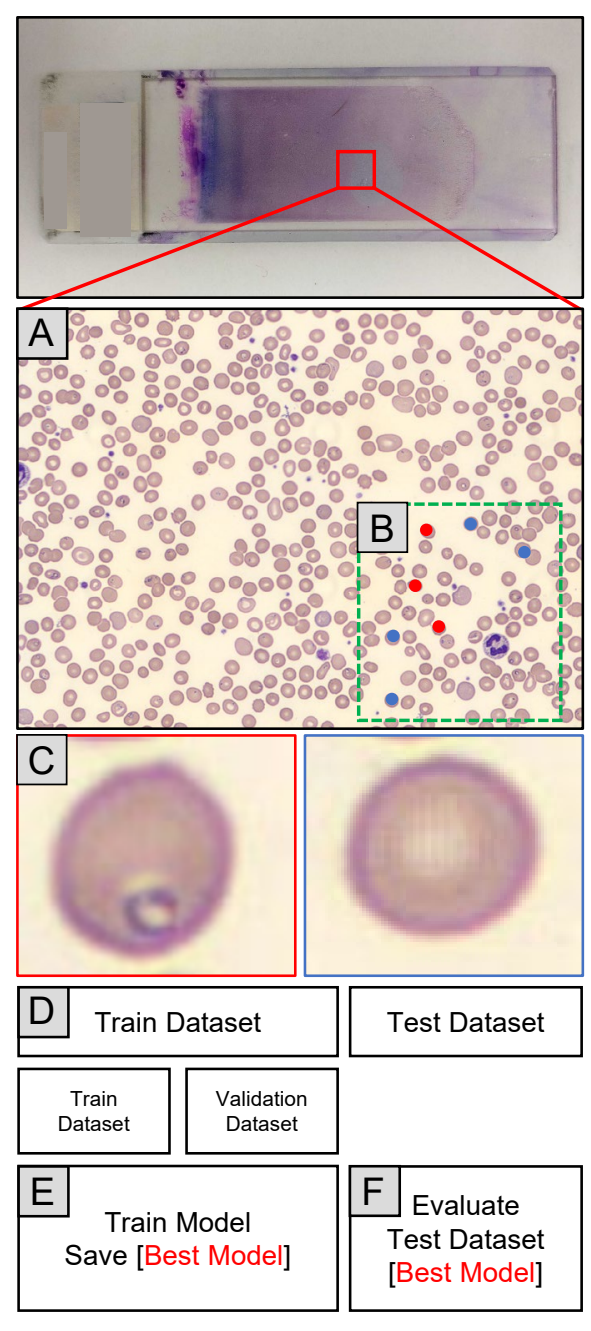




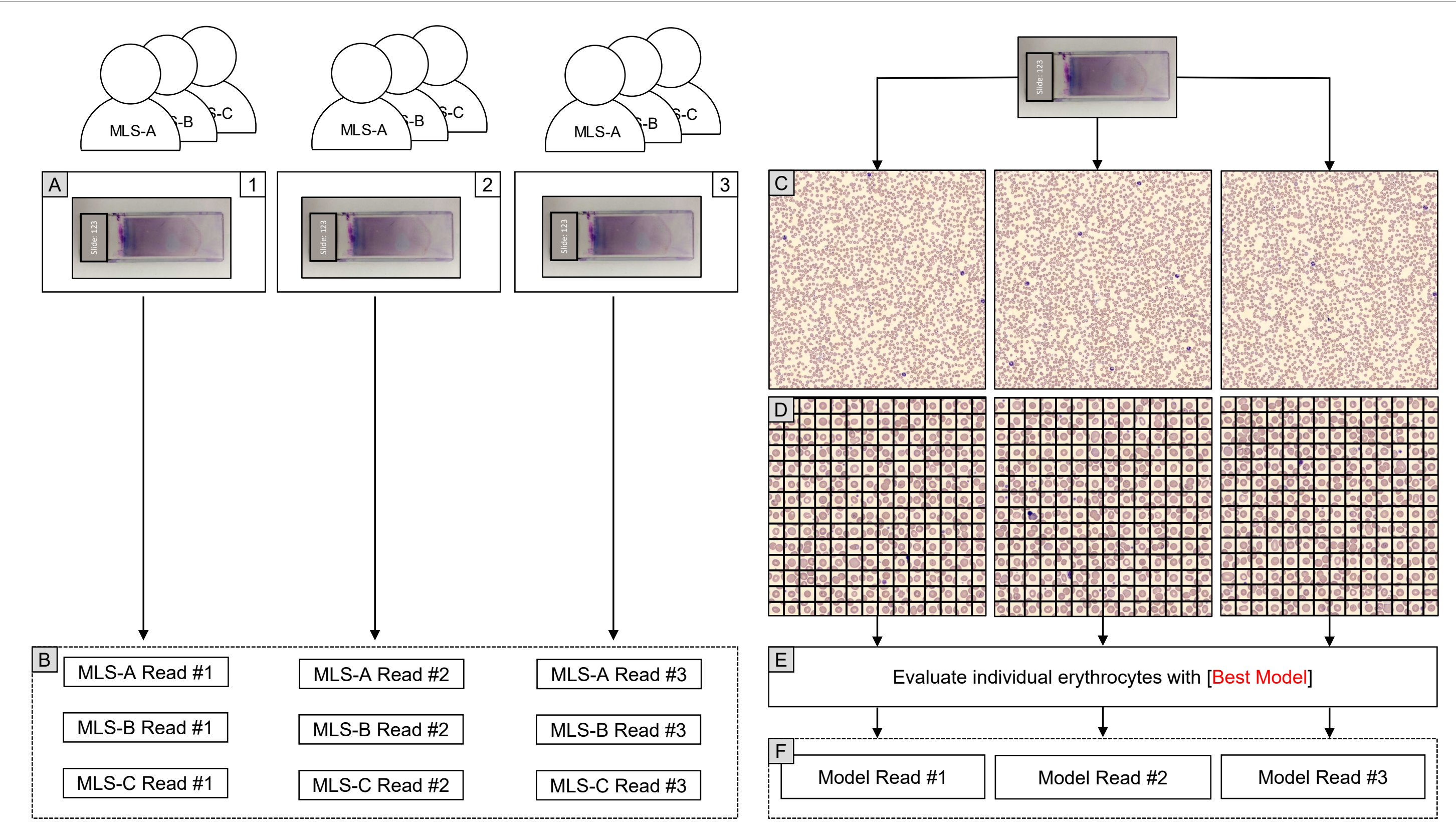



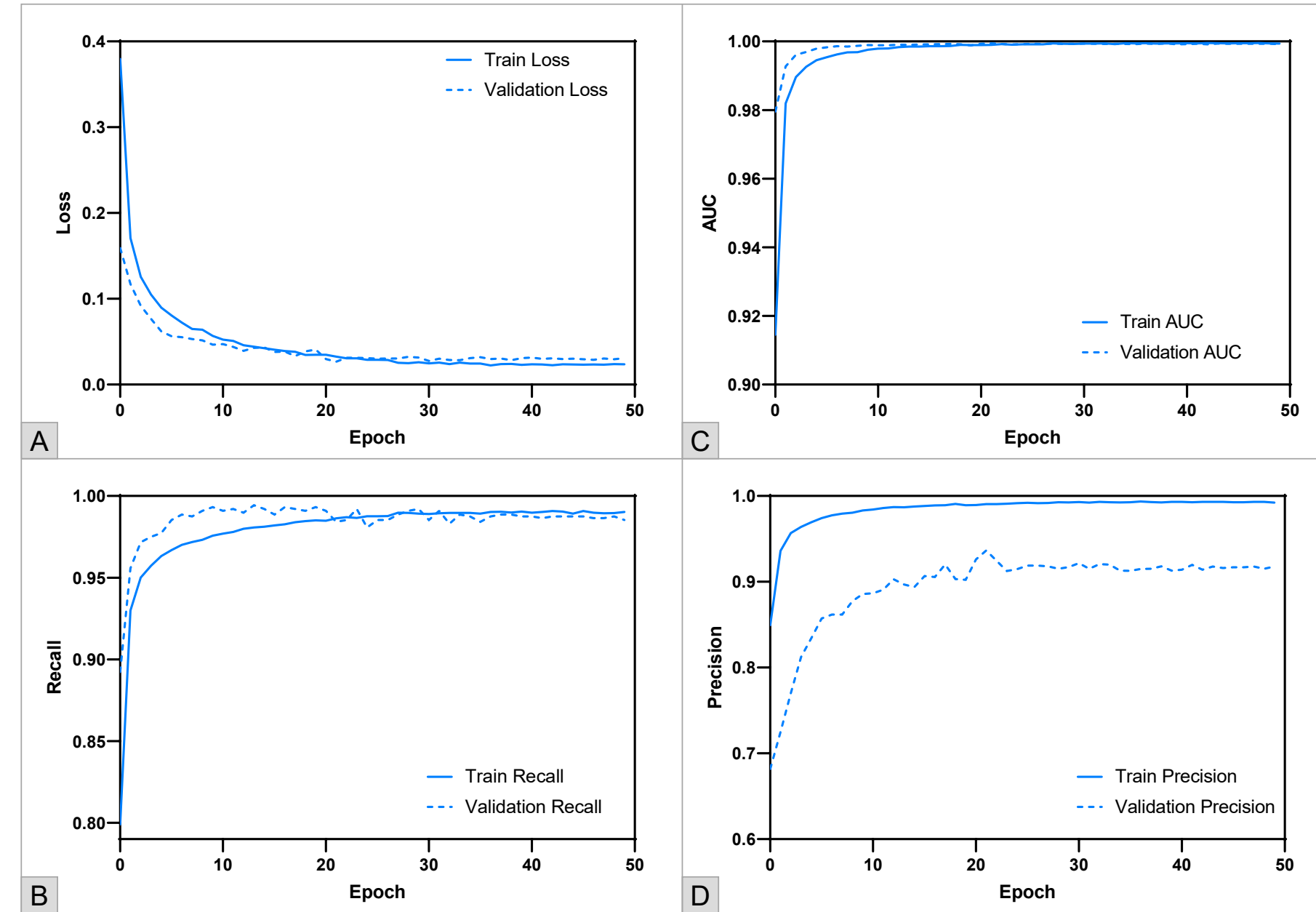


\begin{tabular}{|l|c|c|}
\hline Actual Label & \multicolumn{2}{|c|}{ Predicted Label } \\
\hline & Normal & Parasite \\
\hline Normal & 2258 & 20 \\
\hline Parasite & 0 & 245 \\
\hline
\end{tabular}

A

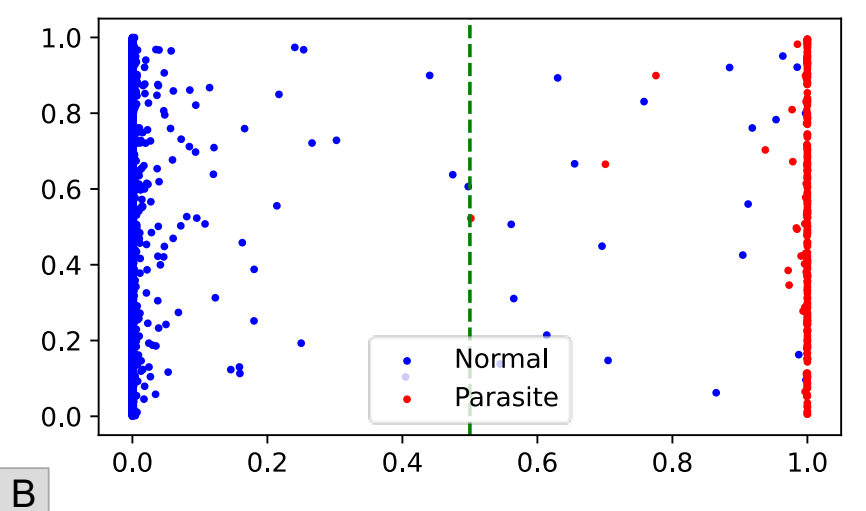




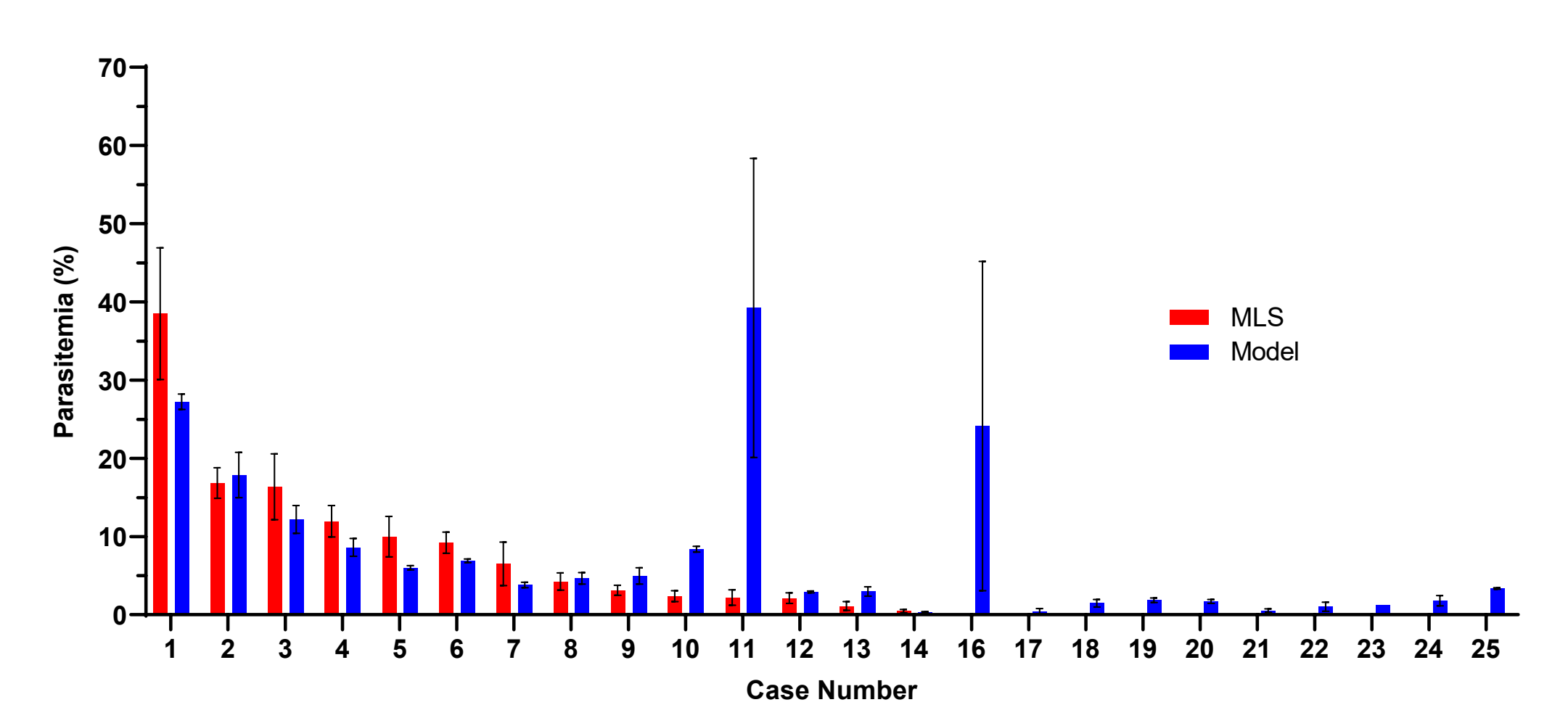




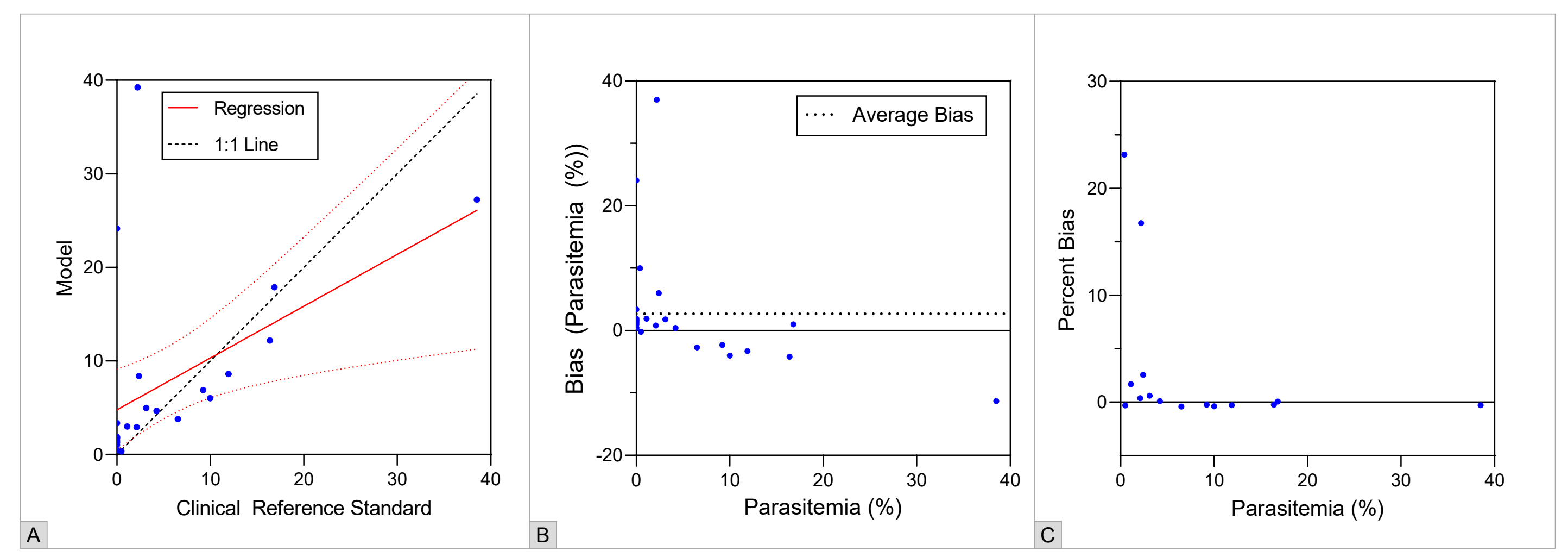




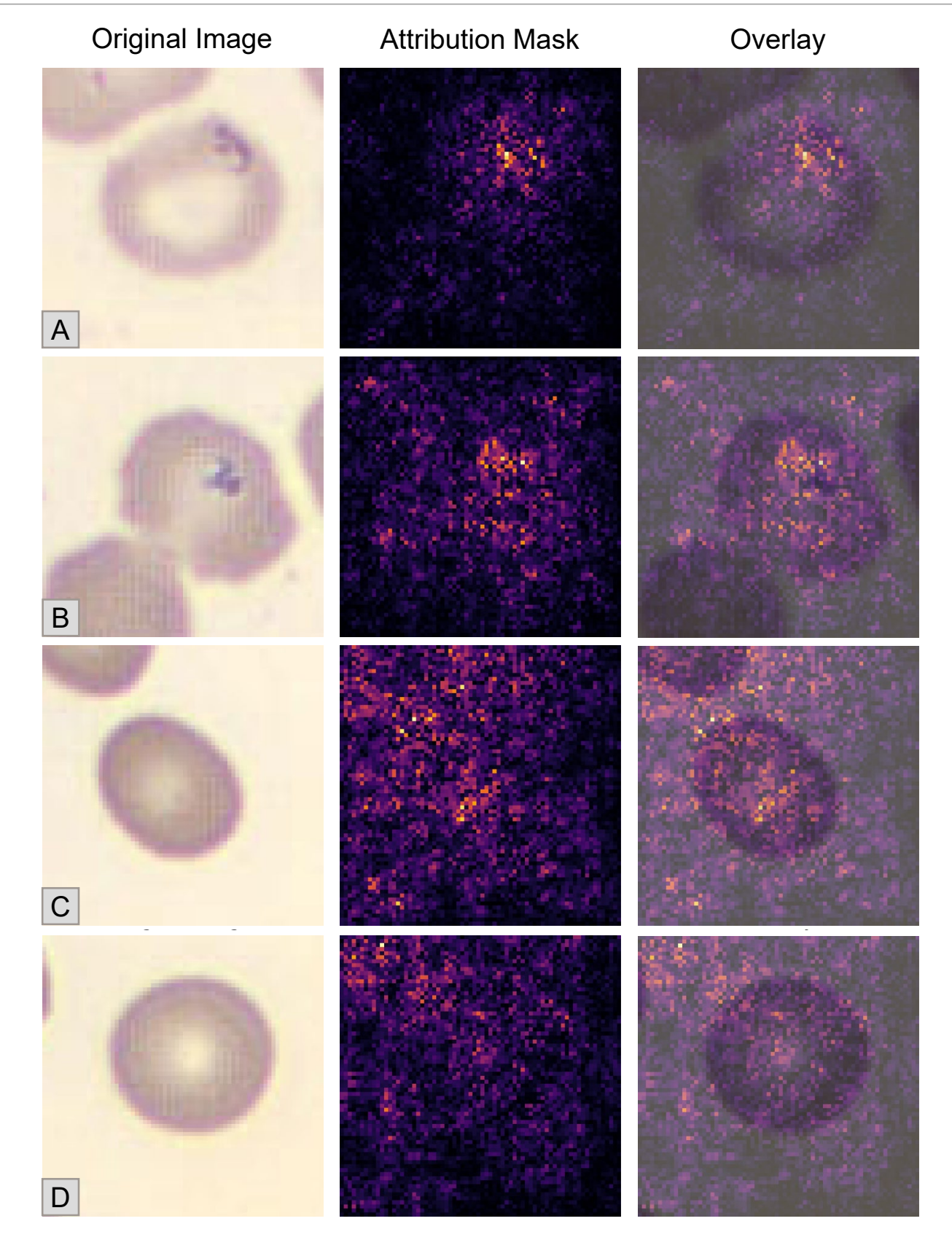




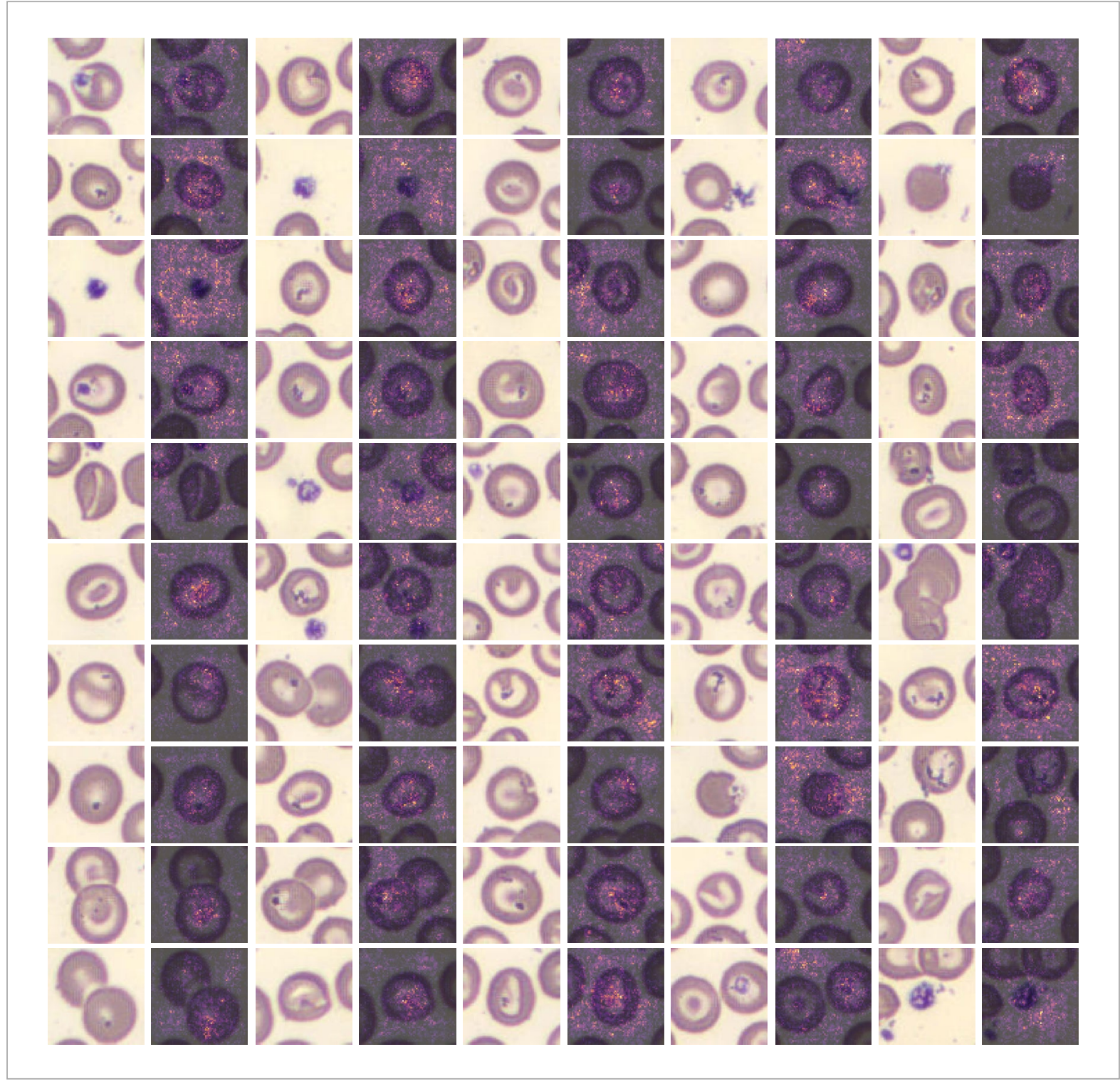

